\title{
Amlodipine Induced Gingival Overgrowth, Unusual Defect and The Impact of Oral Environment: A Case Report
}

\author{
SALOUI Sara ${ }^{1 *}$, ELHOUARI Bouchra ${ }^{2}$, KISSA Jamila ${ }^{3}$ \\ ${ }^{* 1}$ Resident, department of periodontology, Casablanca Dental School, Morocco \\ ${ }^{2}$ Professor, department of periodontology, Casablanca Dental School, Morocco \\ ${ }^{3}$ Professor, head of service of periodontology Casablanca Dental Medical School, Morocco
}

Received: February 2, 2019; Accepted: March 07, 2019; Published: March 20, 2019

*Corresponding author: Dr. SALOUI Sara, Resident in periodontology, Casablanca Dental School, Morocco. Email: sara_saloui@hotmail.fr ; Phone number: (+212) 624580353.

\begin{abstract}
Introduction: Calcium-channel blockers are known for their buccal side effect as Gingival Overgrowth (GO). Although Amlodipine is considered a safe drug, it may induce gingival overgrowth for some individuals, inducing then, an aesthetic prejudice for the patient and causing serious managerial problems for clinicians. This case reports unusual defects of Amlodipine-induced gingival overgrowth, with a large gingival mass that almost completely disappeared only after improving the buccal environment.
\end{abstract}

Case Study: A 51-year old Moroccan woman was complaining of gingival bleeding swelling. The examination revealed a general GO on the labial side, from the 22 to 15 . It involved the entire height of the keratinized gingiva, including papillae on the buccal side. The oral hygiene was really defective with abundant plaque and calculus. The patient had hypertension and daily treated by Amlodipine $5 \mathrm{mg}$ for one year. But she developed the GO just few months before her first visit. The mass, associated with a chronic periodontitis, almost disappeared after scaling and root planning. Such a minimal surgical treatment showed improvement with no drug substitution or reduction. She was regularly followed up for 10 months.

Conclusion: Improvement of oral hygiene, associated to periodontal non-surgical treatment alone, can afford clinical satisfaction. Changing the patient's medication should be the last solution when local measures fail.

\section{Background}

Gingival enlargement is characterized by an increase in the size of gingiva [1]. It is the preferred term for "gingival hyperplasia" or "gingival hypertrophy" [2]. An increasing number of medications are associated with gingival enlargement; they can be broadly divided into three categories: Anticonvulsants, Calcium channel blockers, and Immunosuppressant's. The pharmacologic effect of those drugs is different and directed toward various primary target tissues, but all of them act similarly on a secondary target tissue, which is the gingival connective tissue, leading then to Drug Induced Gingival Overgrowth (DIGO). Amlodipine, a dihydropyridine derivative, is a third generation of calcium channel blockers; it has longer action and weaker side effect compared to the first generation such as Nifedipine. The prevalence of GO in patients under Amlodipine was reported to be $3.3 \%$, which is lower than the rate in patients under Nifedipine, $47.8 \%[3,9-10]$. Gingival overgrowth is observed within few months and gradually evolves after starting the medication. Its appearance seems to have no direct correlation with dose drug, duration of therapy and genetic susceptibility. However, poor plaque control seems to be a commun risk factor [11].

Usually, and initially the defect is painless. The enlargement starts in the interdental papilla and eventually may increase in all directions. When not affected by secondary inflammation, the enlargement looks firm and pink with minute lobulation and no bleeding on probing. Secondarily, the existing enlargement can be oversized and presents large inflammatory features. It is more prominent in maxillary and mandibular anteriors. It is absent in edentulous areas and disappears if teeth are extracted $[1,6,8]$. Pathogenesis is related to Amlodipine action mechanism. The molecule reduces $\mathrm{CA} 2+$ cell influx, leading to a reduction of fibroblast folic acid uptake, inducing then an increase of TIMP-1; the inhibitory Molecule Of Metalloproteinase (MMP1). This latter is essential for the activation of collagenase inside the fibroblast. Consequently, the production of active collagenase decreases and collagen accumulates in gingival connective tissue matrix, leading to a progressive evolution of the GO (Collagen is normally degraded by collagenases) (Figure-1). There is also a probability of genetic predisposition [5,7-9].

\section{Clinical Presentation}

A 51-year old Moroccan woman was directed to the Department of Periodontology, at the Casablanca Dental Medical University, complaining of gingival swelling for few months. She reported spontaneous bleeding, and felt very uncomfortable as the non- painful mass presented an aesthetic prejudice, impairing chewing and speech. Anamnesis reported hypertension daily treated by Amlodipine $5 \mathrm{mg}$ for one year. The extraoral examination 


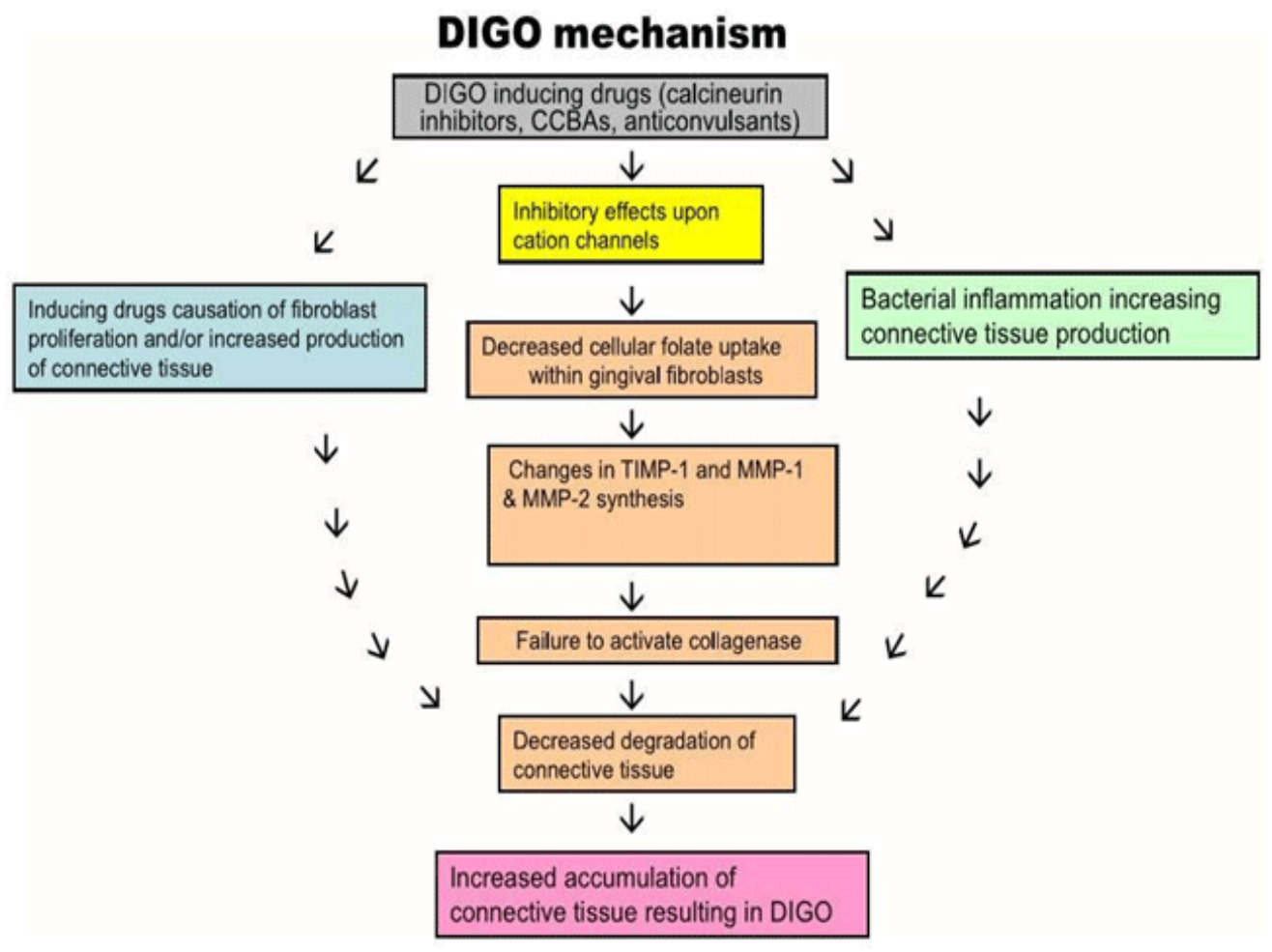

Figure 1: Drug-induced gingival overgrowth mechanism (7)

revealed no adenopathy or facial asymmetry. On the other hand, a fetid breath was noteworthy. The Intraoral examination revealed a generalized GO located on the labial side, with a maximum of swelling on the right maxilla from the 22 to 15 . It involved the entire height of the keratinized gingiva including papillae on the buccal side. The gingival inflammation was generalized and the oral hygiene was defective with abundant plaque and calculus (Figure-2). The GO was soft and non-tender on palpation, but not purulent. Its localization coincided with the presence of a block of unilateral calculus, resulting from the unilateral chewing in addition to the bad hygiene. Its size gradually evolved over time and became unbearable for more than a month. Bleeding on probing was detected on all affected areas. Probing showed periodontal pockets depth 4 to $9 \mathrm{~mm}$ including pseudopockets on the lesion site. All teeth presented mobility grade 2 to 3 . Periapical x-ray showed no radiographic abnormalities related to the lesion. Radiological analysis concluded generalized, deep to terminal, horizontal bone loss (Figure-3).
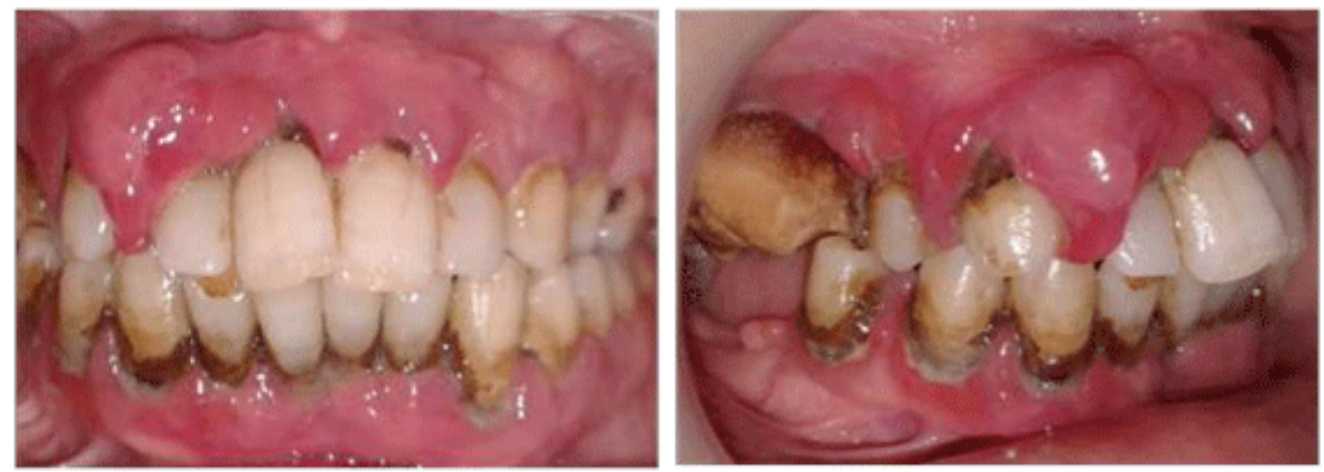

Figure 2: Intraoral examination, lateral and face view. 

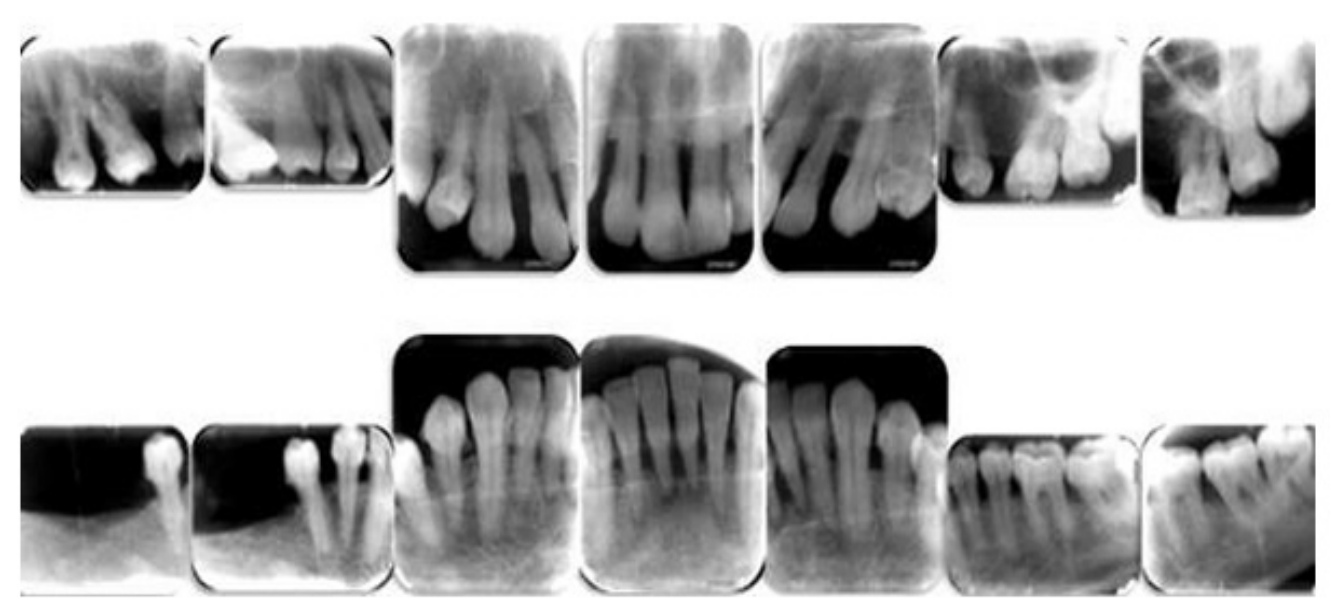

Figure 3: Radiographic evaluation of the patient.

\section{Case Management}

Non surgical periodontal treatment was performed, including intensive oral hygiene instruction, scaling and root planing. For protective measures, the patient used inter-dental brushes with $0.12 \%$ chlorexidine gingival gel, during 2 months, on 12 and 13 . Surgical intervention was performed for resection of the rest of the GO (Figure-4).

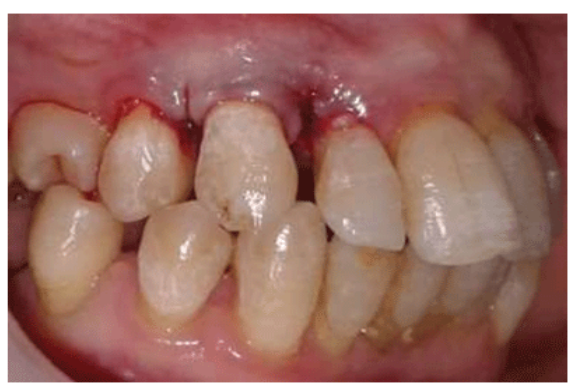

Figure 4: Resection of the rest of GO

Anatomo-pathological examination showed reactive hyper plastic squamous mucosa, slightly parakeratosis, based on an inflammatory chorion. The case was diagnosed as Amlodipineinduced gingival enlargement associated to generalized chronic periodontitis, based on clinical, radiographic and histopathologic features. To improve the comfort of the patient, lingual contention was fulfilled from 33 to 43 . Due to the presence of occlusal trauma between upper and lower incisor-canine sector, a selective grinding of the four mandibular incisors was realized (Figure-5). As they had poor prognosis, teeth 17 and 18 were extracted. In order to prepare prosthetic support teeth, sectorial orthodontic treatment began to close the diastema between the 44 and 45 , as the patient couldn't afford a general treatment. Supportive periodontal care was programmed every 2 months. The patient was motivated and kept a healthy oral hygiene.

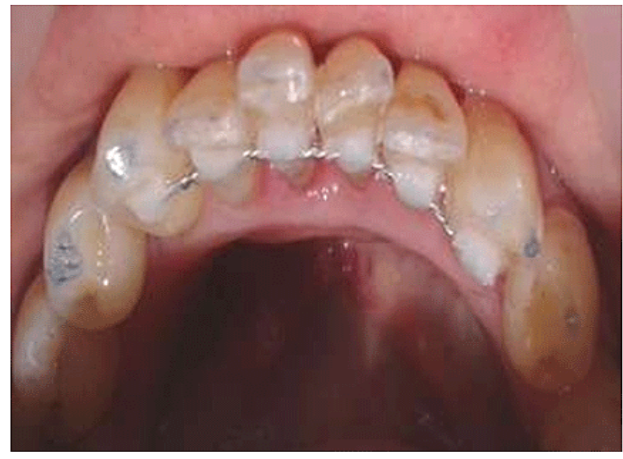

Figure 5: lingual contention and selective grinding.

\section{Clinical Outcomes}

A decrease in size and changes in consistency and texture were clearly visible one week after scaling (Figure-6). 10 weeks after initial treatment; pockets depth reduction was observed (Table1) and GO almost disappeared (Figure-7). Seven months later, after the minimal surgery, there was no recurrence of the GO (Figure-8).

\section{Discussion}

Gingival overgrowth may be due to a direct effect of the drug that regresses upon interruption of drug therapy. However, it is generally agreed that the inflammatory changes caused by the bacteria biofilm synergize with the drug effect to cause overgrowth of the soft tissues. This can be explained by the stimulation of the fibroblasts and therefore the collagen synthesis, after releasing some pro- inflammatory cytokines such as IL-1 $\beta$ and IL6 [4-8].

This suggests that plaque-induced gingival inflammation may be an important risk factor for the development and expression of the gingival changes [3]. From its side, GO promotes bacterial proliferation and plaque accumulation, leading to gingivitis or periodontitis, thus increasing the gingival tissues [8]. In 

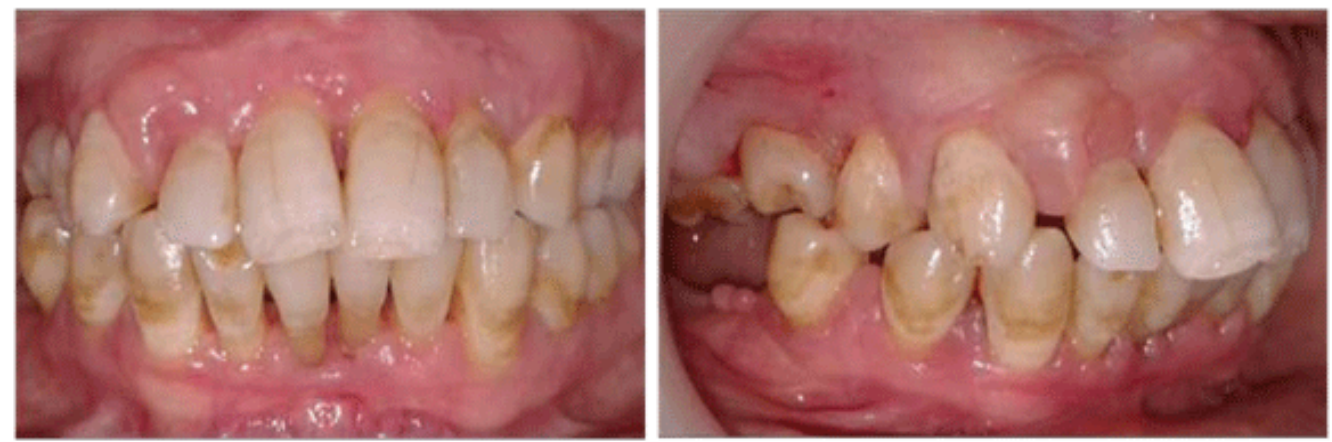

Figure 6: one week after scaling.

Table 1(a): Probing depth before root planning

\begin{tabular}{|c|c|c|c|c|c|c|c|c|c|c|c|c|c|c|}
\cline { 2 - 13 } & 17 & 16 & 15 & 14 & 13 & 12 & 11 & 21 & 22 & 23 & 24 & 25 & 26 & 27 \\
\hline M & 8 & & 3 & 7 & 8 & 5 & 6 & 7 & 5 & 5 & 3 & & 2 & 3 \\
\hline C & 6 & & 3 & 3 & 3 & 5 & 3 & 3 & 4 & 4 & 2 & & 3 & 3 \\
\hline D & 9 & & 5 & 5 & 5 & 8 & 5 & 5 & 7 & 3 & 3 & & 5 & 3 \\
\hline M & 7 & 8 & 4 & 7 & 3 & 7 & 8 & 6 & 5 & 3 & & 3 & 3 \\
\hline C & 3 & 4 & 3 & 3 & 2 & 2 & 4 & 2 & 2 & 2 & & 2 & 3 \\
\hline D & 9 & 7 & 6 & 5 & 7 & 5 & 5 & 8 & 3 & 3 & & 5 & 3 \\
\hline
\end{tabular}

Table 1(b): Probing depth 10 weeks after initial treatment. Pockets depth is clearly reduced, (* bleeding on probing)

\begin{tabular}{|c|c|c|c|c|c|c|c|c|c|c|c|c|c|c|c|}
\hline & & $17^{*}$ & 16 & 15 & 14 & 13 & 12 & 31 & 21 & 22 & 23 & 24 & 25 & 26 & 27 \\
\hline & $\mathbf{M}$ & 5 & & 2 & 3 & 4 & 1 & 3 & 2 & 2 & 3 & 2 & & 2 & 2 \\
\hline 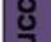 & C & 5 & & 2 & 2 & 1 & 2 & 2 & 2 & 1 & 3 & 2 & & 2 & 4 \\
\hline & D & 5 & & 3 & 2 & 2 & 4 & 2 & 2 & 5 & 2 & 2 & & 2 & 5 \\
\hline & $\mathbf{M}$ & 5 & & 4 & 1 & 2 & 1 & 3 & 5 & 3 & 2 & 2 & & 2 & 2 \\
\hline 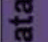 & C & 2 & & 2 & 2 & 2 & 2 & 2 & 2 & 2 & 2 & 2 & & 1 & 2 \\
\hline बुँ & D & 5 & & 4 & 2 & 4 & 4 & 3 & 2 & 2 & 2 & 3 & & 1 & 2 \\
\hline
\end{tabular}

Table 1:
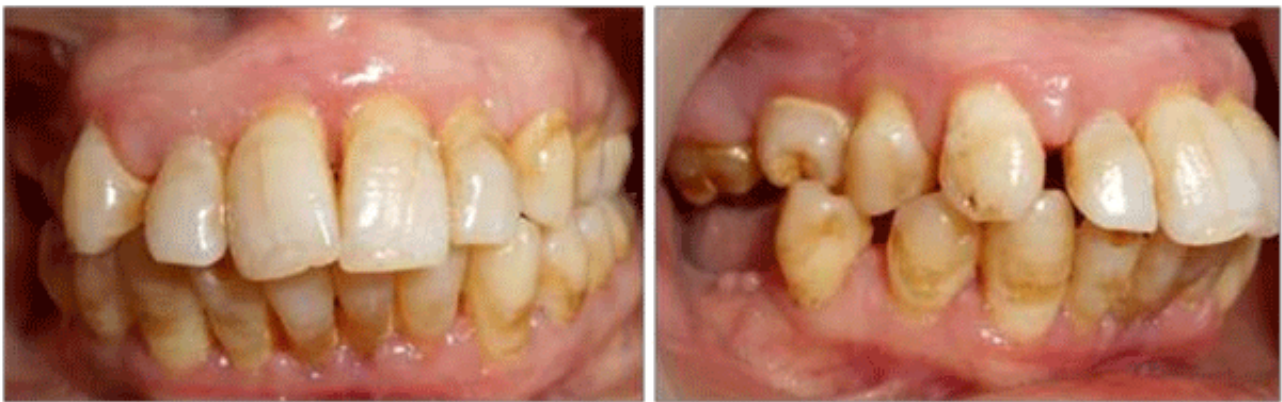

Figure 7: 10 weeks after initial treatment: The GO almost disappeared, despite the minimal recurrence of calculus

Citation: SALOUI S, EL HOUARI B, KISSA J (2019) Amlodipine Induced Gingival Overgrowth, Unusual Defect and The Impact of Oral

Environment: A Case Report. J Dent Oral Disord Ther 7(1): 1-5. DOI: http://dx.doi.org/10.15226/jdodt.2019.001103 

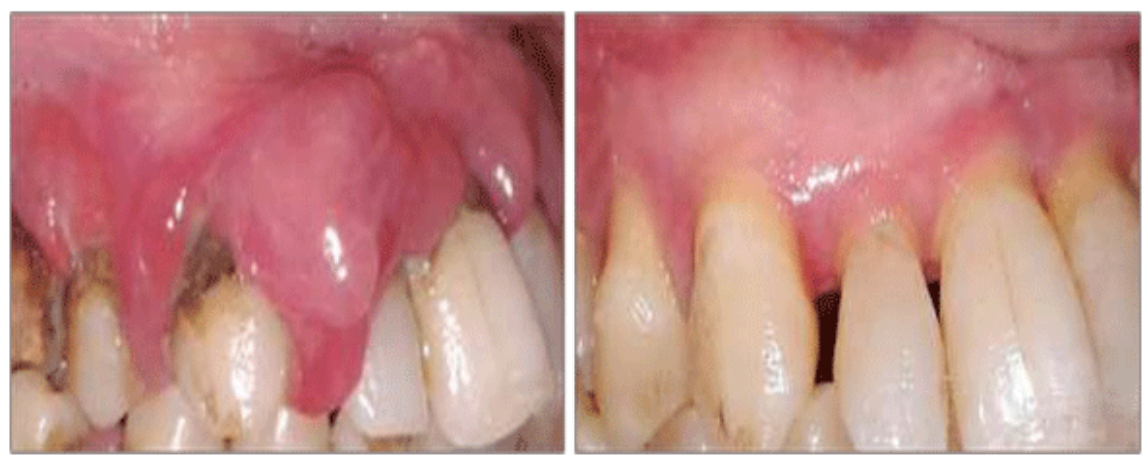

Figure 8: 7 months after surgery.

this case, chronic periodontitis preceded GO. In addition, poor plaque control and remarkable presence of calculus were the local environmental factors that may act as risk factors, and may had contributed to worsen the gingival enlargement. Plaque accumulation and bad hygiene was at a time the cause and the consequence of the GO. The first aim of the treatment was to control plaque accumulation and gingival inflammation. All hygiene methods affording a good plaque control were instructed to the patient, in addition to scaling and root planing. No antibiotic was prescribed, mouthwash based on $0,12 \%$ of chlorhexidine and gel for local application based on $0,05 \%$ chlorhexidine were enjoined. This case demonstrates that even without changing the associated drug, periodontal treatment alone can afford clinical satisfaction. Changing the patient's medication should be the last solution, when local measures have shown limited results [4]. However the possibility of GO recurrence must be considered as long as the patient is under associated medication, in addition to other risk factors [3].Therefore, the patient must be informed about risks, the necessity for a healthy oral hygiene and the importance of supportive periodontal care as key factor prevention. This latter has been recommended for patients taking drugs associated with gingival enlargement every 3-month interval [2].

\section{References}

1. Agrawal AA, Gingival enlargements: Differential diagnosis and review of literature. World J Clin Cases. 2015;3(9:779-788. doi: 10.12998/ wjcc.v3.i9.779

2. Bagtzoglou AD. Drug-Associated Gingival Enlargement. J Periodontol. 2004;75(10):1424-1431. doi:10.1902/jop.2004.75.10.1424

3. Taib H, Ali TBT, Kamin S. Amlodipine-induced gingival overgrowth: a case report. Arch Orofac Sci. 2007;2:61-64.

4. S. Vikrant. S-amlodipine-induced gingival enlargement. Indian J. Nephrol. 2015;25(1):62-63. doi: 10.4103/0971-4065.144428

5. Krishnamoorthy KM, Nair K. Gingival overgrowth due to amlodipine. Indian Heart J. 2016;68(3):431. doi: 10.1016/j.ihj.2016.03.036

6. Taylor BA. Management of drug-induced gingival enlargement. Aust Prescr 2003;26:11-3. doi: 10.18773/austprescr.2003.007

7. Brown RS, Arany PR. Mechanism of drug-induced gingival overgrowth revisited: a unifying hypothesis. Oral Dis. 2015;21(1):e51-61. doi: 10.1111/odi.12264

8. Sibaud V, Vigarios E, Tavitian S. Cougoul P, de Bataille C, Campana F, et al. Gingival management: Practical management. ANN DERMATOL VENER. 2016;143(6-7):467-481. doi: 10.1016/j.annder.2016.04.003

9. Mironiuc-Cureu M, Dumitriu AS, Gheorghiu IM, Stoian IM. Gingival overgrowth as secondary effect of calcium channel blockers administration: A case report. J Med Life. 2014;7(2): 241-245.

10.Gopal V, Brian C, Chainani-Wu N. Amlodipine-induced Gingival Overgrowth with Unusual Presentation as a Gingival Mass and Rapid Regression After Dose Reduction. Clin Adv Periodontics. 2017;7(1):2529.

11. Gaur S, Agnihotri R. Is dental plaque the only etiological factor in Amlodipine induced gingival overgrowth? A systematic review of evidence. J Clin Exp Dent. 2018;10(6):e610-e619. doi: 10.4317/ jced.54715 